\title{
IMPLEMENTING A SYSTEMATIC APPROACH TOWARDS THE DOWNTIME COST
}

\author{
Bhushan B. Malusare, \\ M.E. Students (Construction \& Management), \\ Department of Civil Engineering \\ D. Y. Patil Institute of Engineering \& Technology, \\ Ambi Pune
}

Abstract- The purpose of this paper is to present a sample of how Indian manufacturing companies deal with equipment downtime cost, and further how they analyze its reduction. The study was performed by conducting a web-based survey within Indian firms that have at least 50 employees. The main results obtained from the investigation show that the estimated downtime costs constitute about $23.00-30.00 \%$ from the total manufacturing cost ratio, and $13.00-15.00 \%$ from planned production time. Additionally, the hourly cost of downtime, whether planned or unplanned, is relatively high. However, there is a shortage of systematic models that are capable to trace the individual cost imposed by downtime events. This lack was shown apparently whilst $83 \%$ of surveyed companies they do not have any complete model adapted for quantifying their downtime costs. Moreover, only few companies develop their cost accounting methods such as, activity-based costing (ABC) and resource consumption accounting (RCA) to assimilate and reveal the real costs that associated with planned and unplanned stoppages. Still, the general pattern of downtime cost calculation allocated to direct labour and lost capacity cost. On the other hand, the attempts of decreasing downtime events and thus costs were based on schedule maintenance tactics that supported by overall equipment effectiveness (OEE) tool, as an indicator for affirming improvements. Nonetheless, the analysis indicates the need for optimized maintenance tactics by incorporating reliability-centered maintenance (RCM) and total productive maintenance (TPM) into companies' maintenance systems. Furthermore, the same analysis shows the requirement for better results of performance measurement systems is by implementing total equipment effectiveness performance tool (TEEP). The advantage of such tool is to provide the impact index of planned stoppages in equipment utilization factor. Finally, the lack of fully integrated models for assessing the downtime costs and frameworks for distinguishing the difference between planned and unplanned stoppages are the main reasons behind the continuation of cost in ascending form. Due to that, the improvements will emphasize on areas with less cost saving opportunities. As

\author{
Prof. Hemant Salunkhe \\ Faculty in Department of Civil Engineering \\ Department of Civil Engineering \\ D. Y. Patil Institute of Engineering \& Technology, \\ Ambi Pune
}

a result, this will affect the production efficiency and effectiveness which in return has its influence on costs and thereby profits margin. Further, I have worked on a model which will divide the resources into small activities which will help us to recognise the defects (planned/unplanned) into various categories and suggest the same to different companies in the nearby vicinity.

Keywords: Downtime cost, planned stoppage, Maintenance optimization, Performance measurement systems, Indian manufacturing companies

\section{INTRODUCTION}

The opening chapter mainly displays the motivation factors behind the thesis topic and the intention of approaching such a subject. The construction industry is the massive and fastest growing throughout many countries in the world. Germany is an example of a country that has experienced extremely high infrastructure growth rates in the last 10 or 15 years. Effective management of equipments is crucial for the success of construction firms.

The equipment management practices vary to some extent, among the contactor sizes. Equipment manager's main task is to reduce downtime, achieve optimum equipment utilisation and increase production at minimum cost.

The cost of equipment in a project varies from $10-30 \%$ of the total cost of project, depending upon the extent of mechanisation. Proper planning, selection, procurement, installation, operation, maintenance and equipment replacement policy.

\subsection{Background}

In today's aggressive assembling market, creation productivity and viability are among top business needs. Along these lines, generation hardware turning into the focal concentration of enthusiasm as it is the foundation of the assembling procedure and key execution pointer of efficiency. The necessities of exceptional execution drive organizations to significantly consider lessening their machines downtime recurrence and its noteworthy expenses. 


\section{International Journal of Engineering Applied Sciences and Technology, 2019 \\ Vol. 3, Issue 12, ISSN No. 2455-2143, Pages 27-36 \\ Published Online April 2019 in IJEAST (http://www.ijeast.com)}

Gear downtime happens because of arranged or impromptu stops. In any case, the impromptu stops created by disappointments and unsettling influences event are the most widely recognized surprising elements that have the nonunimportant impact on the general efficiency. Additionally, this interrelation between downtime occasions

and efficiency lies in essence of financial undertone, in which cost and benefit factors are conversely corresponding by methods for diminishing downtime cost and along these lines expanding creation benefit. To this end, keeping in mind the end goal to diminish the downtime cost, reasonable and created costing strategies are expected to figure and follow each and every cost dispensed amid the stoppage point. All exercises and assets that have exhausted while recovering the generation hardware capacity ought to be allotted in view of their genuine expenses.

\subsection{Motivations}

The essential part of costing strategy is to highlight ranges with high-cost investment funds, and of which supervisors continue to actualize upgrades. For example, one express exchange off is between costing techniques and upkeep applications. Profitable support takes a stab at limiting downtime occasions and subsequently cost. Then again, appropriate costing technique can be of much useful to support administrators through surveying the effectiveness of the received upkeep strategy. In addition, it permits the utilization of arrangement scientific demonstrating and reenactment as a contribution to upgrading upkeep technique, specifically, the preventive support procedure. Immediately, a genuine contextual analysis is exceptionally dire in moving toward this point in a coherent way. As indicated by that, Indian assembling industry was decided for this issue as it has seen unfathomable mechanical advance inside generation offices. Also, the framework of such improvement depended on the establishment of mechanical frameworks. In any case, these modern and complex frameworks presented to regular stoppages wherein some of these stoppages are significantly affects creation blackout thus lost benefit [3]. The instance of breaking down hardware and its reclamation is exorbitant and requires numerous assets and spending costs. For those said reasons, Indian assembling industry is viewed as a decent alternative to examine particularly the issues that identified with downtime cost and lessening examination.

\subsection{Problem statement}

The downtime costing methods that have been used by construction companies they are often static in nature and inappropriate of measuring the dynamic nature of production lines. These methods lack the ability of identifying the hidden cost categories and instead emphasized on the direct cost that levied itself According to Traditional cost accounting method the downtime cost of equipment's was so high as they were using the Traditional costing method. In Traditional cost accounting method the action were taken after the breakdown of equipment's.

The cost analysis and the will of adoption proper techniques suited to the situation are the basic factors for the success and therefore, there is need for a rational planning, proper selection and judicious deployment of equipment in relation to the conditions so as to achieve optimum utilisation. It is a common fact that we find a wide variety of construction machines on every construction sites, which make the construction job easy, safe and quicker.

\subsection{Objective of the study}

The objective of the firm is to minimize operation, maintenance, and repair costs, while achieve high utilization of construction equipment. The main objectives of the project work are as follows:

a) To study different methods used for analyzing the downtime.

b) Investigating sites and to check how they deal with the downtime.

c) Offering suggestion for minimizing the downtime and effective utilization of equipments.

Maintenance objectives fall in two categories: the primary objective and secondary objective. The fundamental objectives of a good planned maintenance program are as follows:

1- Eliminate unnecessary maintenance

2- Reduce overall work and maintenance cost

3- Reduce repair parts inventory

4- Extend the operating life of construction equipment

\section{LITERATURE SURVEY}

Mali Pritam A. (2015), the contractual worker's gear arrangement and hardware administration framework greatly affect the benefit of a firm, particularly for temporary workers with substantial interest in gear. The cost of gear in structural building development activities can run from 25 $40 \%$ of the aggregate venture cost. In this paper data given about how the arranged and legitimate support is vital for development gear for better generation. The information given is month to month gear usage on location and different purposes behind misfortunes in development hardware creation. Appropriate arranging, choice, acquisition, establishment, operation and support of development hardware assume vital part underway in development ventures.

Prasannasangeetha.A, (2015), Development gear assumes awesome critical part in development industry, costs as high as $36 \%$ of the aggregate development extend cost, be that as it may, the hardware support has not been given proper consideration and this add to around $40 \%$ of aggregate development extend cost overwhelm. The goal of this 


\section{International Journal of Engineering Applied Sciences and Technology, 2019}

Vol. 3, Issue 12, ISSN No. 2455-2143, Pages 27-36

Published Online April 2019 in IJEAST (http://www.ijeast.com)

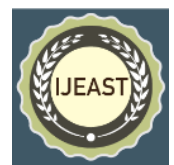

examination is to guarantee that development specialists acknowledge and hold fast to appropriate gear upkeep methodology as successful part of development venture productivity. For assessment of elements a few polls has been readied utilizing this data and circulated between development experts. Point of this paper is to decrease downtime, accomplish ideal gear usage and increment generation at least cost.

Amir H. B., (2013), A deliberate way to deal with sit still time diminishment can essentially support the effectiveness of development preparement amid their lifetime, result in higher general efficiency, and eventually secure general wellbeing and the earth. Towards this objective, this paper depicts examine gone for outlining a system for estimating substantial hardware sit still circumstances amid a development extend. A disseminated sensor system is deployed to impart and introduce measurements about sit without moving circumstances and generation rates and educate extend chiefs and field administrators when sit out of gear time edges are surpassed. The outlined UI includes a graphical portrayal of the site design to imagine the status of hardware progressively in sup-port of venture administration and basic leadership errands. Gathered information will be additionally used to decide energy utilization and $\mathrm{CO} 2$ outflow levels as the venture gains ground. Utilizing reproduction demonstrating, different operational methodologies are assessed from the perspective of gear discharge and sit times.

Rickey A. Cook, (1999), The objective of this review was to build up a crane and overwhelming hardware upkeep get ready for enhance Well being and productivity. XYZ Construction does not have a methodical strategy for keeping up its cranes and substantial hardware. Their way to deal with hardware upkeep could make dangers to specialists and property. This organization understands the potential for misfortune and thinks enhancing their upkeep plan will help relieve this issue. So as to finish this, the paper utilized three stages to build up a support plan.

Ilias Naskoudakis, (2016), An extensive collection of writing has been devoted to research contemplates on development hardware. Numerous themes were talked about and dissected, and different conclusions have been accounted for. Nonetheless, inquire about papers distributed with respect to construction hardware, are profoundly differentiated, and there is an absence of precise examination and arrangement. Subsequently, an entire comprehension of the subject is unrealistic, nor is the assessment of any future research bearing. A meta-investigation of the most recent diary papers committed to development apparatus would not just portray the fields the scholastic research was focused on however would furthermore uncover potential crevices for future research. In the ebb and flow examine, through a precise survey of the scholastic writing distributed in the course of the most recent decade, primarily distinguished by means of online databases, principle look into topics, for example, enhancement, support/downtime, efficiency, mechanical autonomy and computerization, administrator ability, development, and environment are resolved and talked about, with future research headings recommended. The result of this paper will encourage future scientists to build up an assortment of learning of advance on development hardware and its potential capacities and provide future research headings on this issue.

D.G. Proverbs, G. D. et al. Taking after a nitty gritty writing audit, eighteen common issues confronting the UK development industry are recognized. The seriousness of these issues as opined by experienced UK development organization executives, gotten through a poll review, is consequently displayed. Discoveries uncover that the two severest issues are thought to be the poor picture and notoriety of the business, aligned with a dominance of ,cattle rustler manufacturers ${ }^{\text {ee }}$. Configuration changes are positioned third, trailed by late installments, time restrictions and dependence on focused offering methodology. In light of these perspectives it is prescribed that the business ${ }^{\text {ee }}$ need ought to be towards nullifying corrupt firms in the residential repair, upkeep and change area, in this manner driving towards the advancement of a more expert picture. This ought to be consolidated with an endeavour by all development members to annihilate the current antagonistic nature of the business. A long haul vital arrangement is required if such nonspecific extensive issues are to be tended to adequately in the new millennium.[6] The development venture can fluctuate from to a great degree gainful to scarcely justified, despite all the trouble and here and there wind up costing the contractual worker more than what he or she is getting paid to finish it. In development industry the point of venture control is to guarantee the undertakings complete on time, inside spending plan and accomplishing other venture exercises. Time and cost are two fundamental concerns which increment significance of cost diminishment strategies. Diminishment of cost of development is a consistent objective for development industry. One method for decreasing development cost is to create imaginative innovations and also philosophies to expand profitability. This paper takes care of sorts of expense, elements influencing expense of ventures and additionally exchange on accomplishment of acceptable consequences of time and cost by applying cost decrease techniques.

Urmila A Mahadik, (2015), Development hardware assumes extraordinary noteworthy part in development industry, costs as high as $36 \%$ of the aggregate development extend cost, notwithstanding, the gear support has not been given suitable consideration and this add to around $40 \%$ of aggregate development extend cost overwhelm. The goal of this 


\section{International Journal of Engineering Applied Sciences and Technology, 2019 \\ Vol. 3, Issue 12, ISSN No. 2455-2143, Pages 27-36 \\ Published Online April 2019 in IJEAST (http://www.ijeast.com)}

examination is to guarantee that development professionals acknowledge and stick to legitimate hardware support methodology as powerful part of development venture benefit. The review evaluated this target using Investigatory Survey Research Approach (ISRA) strategy. Five (5) distinctive basic, however firmly related indispensable methodologies of compelling development gear administration were distinguished. An aggregate number of sixty-five (65) very much organized polls were managed to eight diverse development organizations with character of $\mathrm{A}$, $\mathrm{B}, \mathrm{C}, \mathrm{D}, \mathrm{E}, \mathrm{F}, \mathrm{G}$ and $\mathrm{H}$ to gather quantitative and subjective information on how gear support has been taken care of in some haphazardly chose development organizations situated in Abuja, Minna and their environs. The contextual investigation regions were chosen as a result of their center overwhelming development ventures exercises. Fifty-seven (57) which speaks to $87.7 \%$ of the aggregate polls were recovered and broke down. The information gathered was subjected to recurrence investigation technique. The review uncovered that $51.5 \%$ of the development organizations surveyed don't append high need to gear upkeep and this contributed significantly to development extend cost invade coming about because of hardware breakdown. Dependability of development gear incredibly relies on upon the support. It is suggested that development experts bear the cost of the chance of gear upkeep technique as a major aspect of development venture administration. This will help lessen costs, likelihood of unforeseen disappointment, upgrade use and limit hardware downtime, which will consequently build the general development ventures profitability.

\section{EXPERIMENTAL SET UP}

In this step we get detailed idea about the previous thesis done, after the detailed study it was noted that there are some laggings which are still affecting the cost of construction project. This encouraged me to get into the subject and do the detailed thesis, so that downtime cost of equipment's used in a construction industry to be minimized.

*** CASE - I***

3.1 SITE DETAILS:

Name of site: Sheetal Complex

Site Address: Wadki Hadapsar Pune..

Client: SSP Technology

Contractor: Sai Costruction

Type of Building: Commercial

Name of Project Manager: Mr. Shailesh Jagtap

Name of Engineer: Mr. Sanjay Shelar
Area of building: 3500 sq.m.

3.2. Observation, Study \& Analysis of the existing process:

In this step I observed the whole ongoing system which is used in daily construction practice. The record such as activity log book, work hindrance register, etc. were studied in detail. After the study of the ongoing system it was noted that there were some lags in system which cases downtime of construction equipment's.

\subsection{Discussion}

A brief discussion meeting was held at site with site team as well as some of the staff from head office. In this meeting results of observation and its study were presented in front of them. After seeing the results, they were agreed to do some changes in the system, and for the same I suggested them to follow the system which were designed by me and Babu Sir. Some suggestion was agreed by them so as to reduce downtime cost of equipment's.

\subsection{Implementation}

Implementation of a new system was started after the approval of management immediately. In this system some changes were done which are as follows:

1. Social Changes

2. Reduction of Communication Gap

3. Changes in Maintenance Strategy

4. Daily Inspection Process

3.5. Analysis

After the Implementation of new system, the work measurements were recorded on monthly basis. This data recorded were analyzed for the final results and the results of analysis were submitted to the Project Manager.

\subsection{Study of Analysis}

After the analysis of the record which is gathered and recorded after making changes in the system, the detailed study of analysis were done and presented in front of the authority.

\subsection{Result}

The result of work measurement was found so useful to minimize downtime cost as it reduces $25-30 \%$ more downtime cost with compare to previous method.

**** CASE - II****

After studying about the losses incurred by different construction equipments, a focus was on narrow approach towards the study regarding different losses and to categorise them systematically so that we can minimize the downtime to the most extreme level. 
Different construction sites were surveyed (Commercial/Residential) and a study based questionnaire were prepared. From that questionnaire it was noted that out of six different companies only one company gave little attention towards the downtime losses of equipments rest other did not utilize any method for reducing the downtime as they were not aware about these complex methods.

Our study focuses on analyzing the different methods that are being used for downtime calculation, conducting survey based on how many small/medium/large construction companies consider about their equipment's downtime specially unplanned, preparing a new and innovative study on downtime and approaching the companies regarding the awareness of loss due to downtime.

\section{RESULT \& DISCUSSION}

Table no.1.Actual Onsite Equipment

\begin{tabular}{|c|l|}
\hline No & Name of equipment's \\
\hline 1 & Mega Crane \\
\hline 2 & Bar Bending Machine \\
\hline 3 & Bar Cutting Machine \\
\hline 4 & Transit Mixer \\
\hline 5 & Vibrating Needle \\
\hline 6 & Diesel Generator \\
\hline 7 & Concrete Pump \\
\hline
\end{tabular}

\subsection{Mega Crane Activity:}

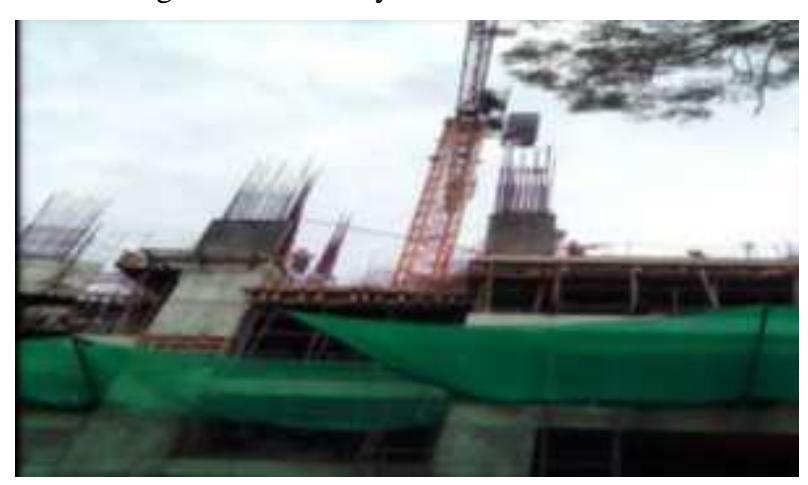

Figure.No.1 Mega Crane
Concreting by Mega Crane of the most efficient task, the efficiency depends upon the structure concreting to be done. For a structure like column, the tower crane can lift about 10 cu.m of concrete per hour.

1. Cost of concrete/cu.m $=$ Rupees 5000

2. Cost of concrete done per hour $=8 * 5000=40000$

If the tower crane is sudden breakdown for an hour, it will affect the cost of the project as follows:

Cost of concrete + Labor Cost (1mason, 2helper); i.e. $=$ $40000+1500+2 * 350=42,200$.

We can also find the affected cost on project if the tower crane is breakdown for 1 day: In 1 day if you are planning to do a concrete quantity 24 cu.m of a column $\&$ beam and your tower crane suddenly breakdown after the 2 concrete vehicles reach at site, in this case the total affected cost on your project is $12 * 5000+1500 * 2+350 * 3=64,050$.

Sometime tower crane is idle as the operator of tower crane is on a shore break or lunch break. A short break takes $30 \mathrm{~min}$ to resume his work where Lunch break takes 1.5 hours to resume the work. If an operator is on a short break tower crane remains idle for half hour which will affect the cost of the project.

4.1.1. Considering above points I have made some changes in our system:

a. Social Changes:

In this we have arranged the alternate operator for mega crane, also the shift wise working system was implemented. In this system before any one operator goes for a break, he gives charge to another one so as to not keep tower crane idle. By implementing this system we achieved our desired goal with full efficiency and utilization of machine. Due to this implementation our cost of idleness reduced by 20 to $25 \%$.

\subsection{Name of Equipment: Bar Bending Machine}

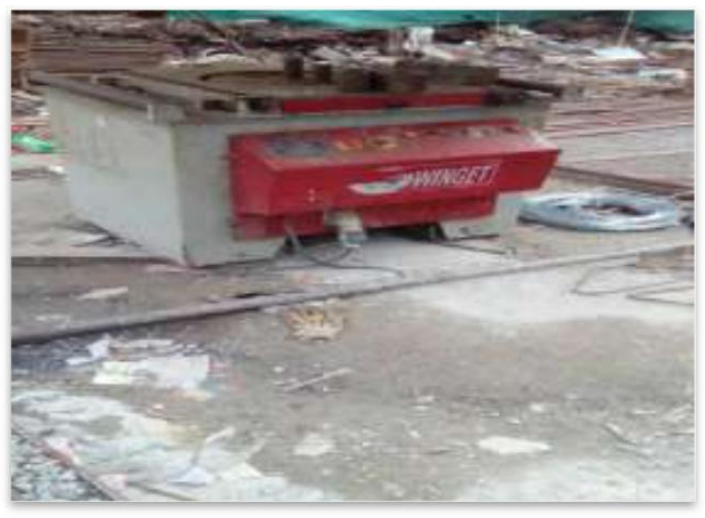

Figure.No.2 Bar Bending Machine 


\section{International Journal of Engineering Applied Sciences and Technology, 2019 \\ Vol. 3, Issue 12, ISSN No. 2455-2143, Pages 27-36 \\ Published Online April 2019 in IJEAST (http://www.ijeast.com)}

\subsubsection{Activity: Reinforcement work}

The capacity of bar bending machine is to bend 4-5 tonne of steel per 8 hours, this mean the capacity of bending machine per hour is equals to $5 / 8=0.625$ tonne per hour . In this case there is only one operator and two helpers to execute the work, if the operator goes for a break the helper and the machine is idle for that time period. If your machine is idle for an hour your project cost affect as follows:

1operator +2 helpers +2 fitter +2 helper $=600+350 * 2+$ $2 * 500+2 * 350=3,000$ Rs. (Labour Charges)

As the reinforcement work is delayed the shuttering can't be done due to which carpenter and there helper also have to sit idle, i.e. $2 * 500+2 * 350=1700$ Rs. As these activity gets delayed all further activity gets delayed and finally your project gets delayed which leads you the increase the construction cost.

4.2.2. Considering above situation I have done some changes in our existing working system:

a. Preventive Maintenance:

Here we use preventive maintenance so that sudden breakdown of the machine does not occurs and the work goes on fluently. AMC is given to third party for monthly basis maintenance as well as daily inspection of machine is done by our MEP incharge so as to prevent any sudden breakdown. This helps us to reduce downtime of machine till 20-30\%.

\section{b. Social Changes:}

The operator was given one helper who was trained with the job (Bar Bending Operation) he have to do in absence of operator. In this case when the operator goes on a short break or Lunch break, the helper continues the job so as to not keep the machine idle at that time. Due to this the capacity of machine was fully achieved and the production was increased to 4.5 tonne per day.

\subsection{Name of Equipment: Transit Mixer}

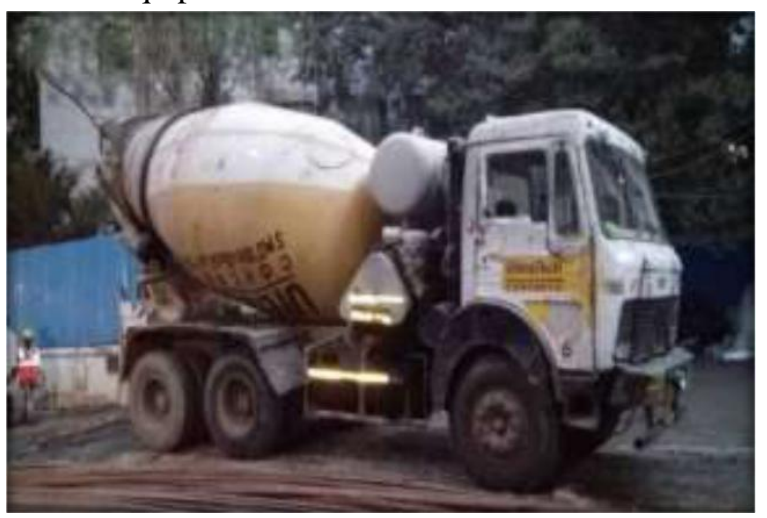

Figure.No.4. Transit Mixer 4.4.1

\section{Activity: Concreting}

Transit mixer plays an important role in the activity of concreting; it acts as a mediator between RMC plant \& Construction site. Averagely transit mixer carries $6 \mathrm{cu} . \mathrm{m}$ of concrete which cost 24,000 Rupees, the workability of concrete is of 3 hours and the transit mixer takes approximate 1.5 hours for transportation from RMC plant to construction site. If a transit mixer fails at the time of transportation and not able to reach site within 3 hours, the concrete is rejected and it cost as follows:

Concrete Cost +Driver Charges +Fuel Charges +Breaking of concrete by breaker which is set in transit mixer due to failure of transit mixer (2 labour for 2 days).

i.e. $=24,000+600+300+800 * 2=26,500$ Rupees.

Considering above loss I finalize the maintenance system and stream lined it, the finalized system was as follow:

1) Every driver will check the Transit Mixer before leaving the plant and after completion of work when he parks the vehicle to plant.

2) Monthly maintenance of a vehicle to be done.

3) Checking of the mixer to be done on daily basis.

4) Checklist to be done on everyday basis.

By applying above system it was observed that the failure of transit mixer was very minor than it was before $\&$ it saved a cost about 26,500 Rs. for a project.

\subsection{Name of Equipment: Vibrator Needle}

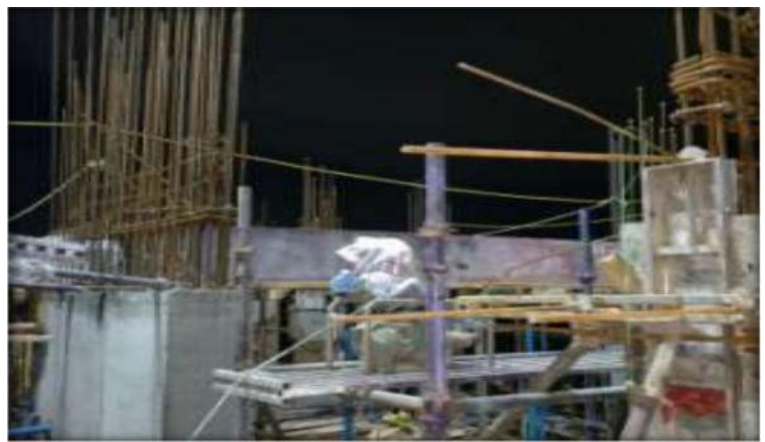

Figure.No. 5 Vibrator Needle

Vibrator needle is used for compaction of concrete at the time of casting. If the vibrator needle is breakdown at the time of casting, the concrete is not well compacted and the honeycomb occurs after deshuttering of structure. If the honeycomb occurs it is to be rectified with chemical mortar and in case of major honeycombing in column the structure is to be breaked.

The above activity will affect your project cost as follows: 


\section{International Journal of Engineering Applied Sciences and Technology, 2019 \\ Vol. 3, Issue 12, ISSN No. 2455-2143, Pages 27-36 \\ Published Online April 2019 in IJEAST (http://www.ijeast.com)}

\subsubsection{In case of minor honeycombing:}

Repairing cost+ chemical mortar cost (Fairmate) $(1$ mason+1helper $)+(4000$ per bag $)$ i.e $(500+350+4000)$ Total cost in case of minor repairing $=4850$ Rupees.

\subsubsection{In case of major honeycombing:}

Shuttering cost + Concrete cost + Labor cost + Demolishing Cost + Housekeeping cost + Re shuttering cost + Concrete cost + Labor cost

$(500+350 * 2)+(5000)+(500+350 * 2)+(350 * 2)+(350 * 2)+$ $(500+350 * 2)+(5000)+(500+350 * 2)$

Therefore total cost $=16200$ Rupees.

\subsection{Name of Equipment: Diesel Generator}

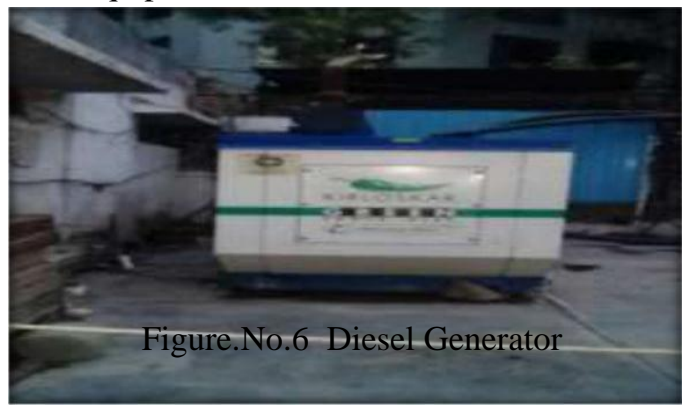

This is the machine which is used as a backup in case of cutoff of light supply, but in case if the Diesel Generator is not working the most labor on site will be idle and the work will be stopped.

This stoppage of work will affect very high on the site budget which is shown below:

Fitter and there helper are not able to cut and bend the steel which cost Rs. 9400, as well as Carpenter are not able to cut the ply which will cost Rs. 10200.

Also the tower crane operator $(2$ nos $)$ remains idle. i.e $=$ $600 * 2=1200$.

Total impact of breakdown of Diesel Generator = $9400+10200+1200=20800$.

This impact is very high for one day breakdown.

\subsection{Name of Equipment: Concrete Pump}

\subsubsection{Activity: Concreting}

Pumping capacity of concrete pump per hour is $15 \mathrm{cu} . \mathrm{m}$ where as it on an actual it pumps 6-8 cu.m of concrete, this lag of pumping of concrete affects financially on the project. Per cu.m rate of pumping of concrete is Rs. 300 means per hour cost is $15 * 300=4,500$. Actual production cost per hour is $8 * 300=2400$. The difference between actual and theoretical cost is $4500-2400=2100+$ labour (Rigger) sits idle which cost $300 * 5=1500$.
4.7. After analyzing why there is difference between actual \& theoretical cost it was observed that there was a communication gap between the site team and plant team for ordering the concrete.

By eliminating this communication gap the ordering sequence of concrete is stream lined. After eliminating this communication gap it was observed that the pouring capacity of concrete pump was increased to $12-13 \mathrm{cu} . \mathrm{m}$ per hour where as prior it was $8 \mathrm{cu} . \mathrm{m}$ per hour. The lag is now $1 \mathrm{cu} . \mathrm{m}$ which cost 300 Rs. In this case we have achieved $90 \%$ of efficiency of a concrete pump.

4.8. Considering above points we have done some changes which are as follows:

As the cost of vibrator needle machine is not so expensive, we purchased two spare needle machines which are useful when the other needle is breakdown. The electric supply of needle is checked on day to day basis so as to prevent breakdown of vibrator needle. Training was given to the labor those who are operating the needle at the time of concreting so as to prevent sudden breakdown due to short circuit due to high pressure on it.

\begin{tabular}{|r|l|l|l|l|}
\hline $\begin{array}{l}\text { Sr. } \\
\text { No }\end{array}$ & $\begin{array}{l}\text { Name of } \\
\text { Equipment }\end{array}$ & $\begin{array}{l}\text { Cost } \\
\text { Without } \\
\text { Failure } \\
\text { (In Rs.) }\end{array}$ & $\begin{array}{l}\text { Cost } \\
\text { With } \\
\text { Failure } \\
\text { (In Rs.) }\end{array}$ & $\begin{array}{l}\text { Difference } \\
\text { in Cost } \\
\text { (In Rs.) }\end{array}$ \\
\hline 1 & Mega Crane & 40000 & 42000 & 2000 \\
\hline 2 & $\begin{array}{l}\text { Bar Bending } \\
\text { Machine }\end{array}$ & 3000 & 4700 & 1700 \\
\hline 3 & Transit Mixer & 24000 & 26500 & 2500 \\
\hline 4 & Vibrator Needle & 25050 & 50100 & 25050 \\
\hline 5 & Diesel Generator & 1500 & 19600 & 18100 \\
\hline 6 & Concrete Pump & 4500 & 8400 & 3900 \\
\hline & TOTAL & 98,050 & $1,51,300$ & 53,250 \\
\hline
\end{tabular}

Table 02 Comparative Calculation

\subsection{Summary}

Table 4: Represents difference in cost before breakdown of equipment and after breakdown of equipment

\subsection{Result:}

By using Activity based costing method we have reduced cost due to downtime of equipment by about $35 \%$. Before using ABC method we were using Traditional method in which we used to cost Rs. 1,51,300 as downtime cost whereas after using $\mathrm{ABC}$ method the downtime cost were reduced by Rs. 53,250. As the downtime is decreased the overall delay in work due to downtime is decreased which results in the Timely completion of the project.

*** CASE - II*** 
4.11 Summary

Information of sites surveyed:

\begin{tabular}{|l|c|c|}
\hline Name of Site & Type of Company & $\begin{array}{l}\text { Method adopted for } \\
\text { Downtime losses }\end{array}$ \\
\hline Shriram Infracon & Small & No \\
\hline $\begin{array}{l}\text { Sadguru } \\
\text { Developers }\end{array}$ & Small & No \\
\hline $\begin{array}{l}\text { Maharatna } \\
\text { Developers }\end{array}$ & Small & No \\
\hline $\begin{array}{l}\text { Arihant Vastushilp } \\
\text { Propcon }\end{array}$ & Medium & No \\
\hline $\begin{array}{l}\text { Siddhatech } \\
\text { Developers }\end{array}$ & Medium & No \\
\hline $\begin{array}{l}\text { Mahalaxmi Group } \\
\text { SP Construction }\end{array}$ & Medium & No \\
\hline Rohan Leher 2 & Large & Yes (ABC Method) \\
\hline
\end{tabular}

From the above table we can clearly see that only two companies out of eight is aware about the downtime losses and has adopted a method for reducing downtime cost of construction equipments. From the above data we can clearly conclude that approximately $2 / 8$ or $2 / 10$ is the ratio in Pune regarding the companies considering downtime losses of construction equipments.

Based on the literature and above study, following step wise losses were divided so that we can study the losses in details, know them and simultaneously take actions against them.

For minimizing the downtime cost we must initially understand that downtime cost of equipment and for reducing this we will have to increase the overall effectiveness of the equipments.

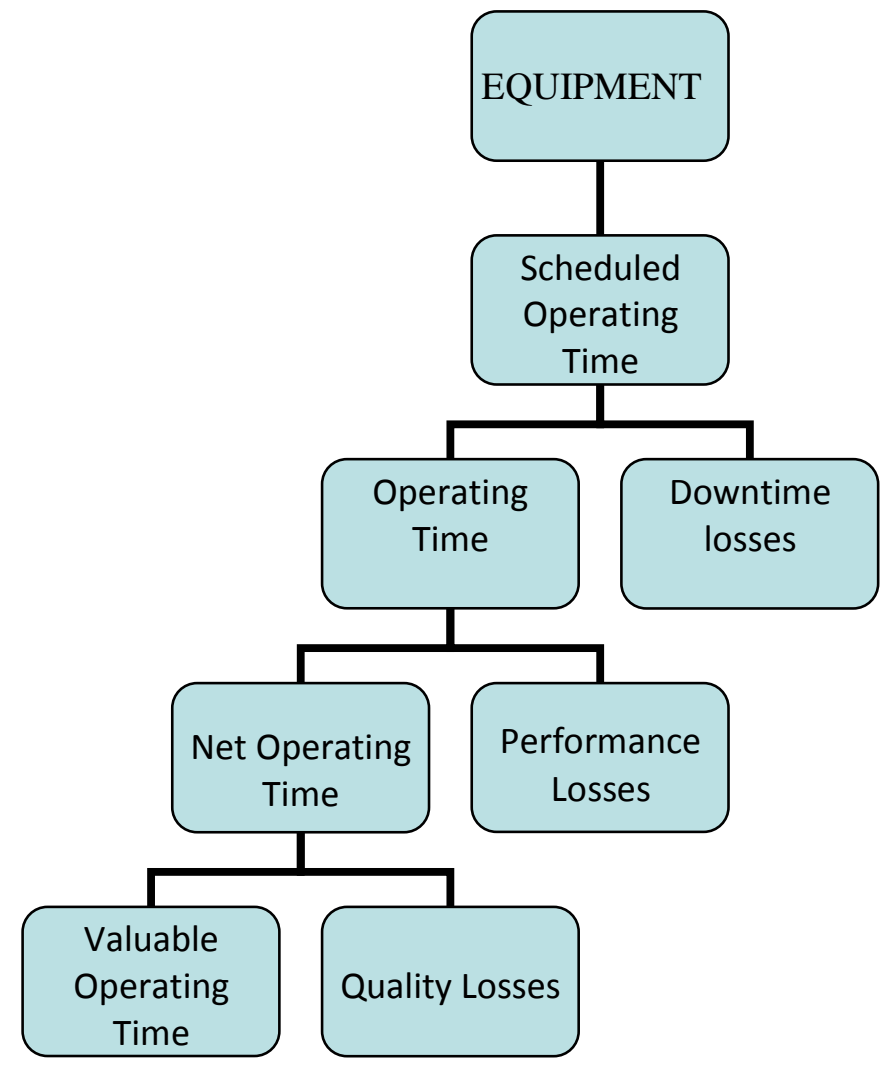

In the above flowchart we can clearly see three types of losses those are, Downtime losses, Performance losses and Quality losses. From the above flow chart we can easily conclude that there are three main factors that need to taken into consideration so as to increase the overall effectiveness of the equipment and those are:
1- Availability of Equipment
2- Performance rate
3- Rate of quality products

Downtime losses are related to the availability of equipments and time of usage. Performance losses deals with performance efficiency and Quality losses are related to Rate of quality of products. 


\begin{tabular}{|c|c|c|}
\hline $\begin{array}{l}\text { Type Of } \\
\text { Loss } \\
\end{array}$ & Category & Calculation \\
\hline $\begin{array}{l}\text { Equipment } \\
\text { failure }\end{array}$ & \multirow{2}{*}{$\begin{array}{l}\text { Downtime } \\
\text { Losses }\end{array}$} & \multirow{2}{*}{$\begin{array}{l}\text { Availability }=(\text { Actual } \\
\text { Operating Time / Scheduled } \\
\text { Operating Time }) \text { x } 100\end{array}$} \\
\hline $\begin{array}{l}\text { Setup, } \\
\text { Adjustment } \\
\text { s, Planned } \\
\text { downtime, } \\
\text { Breaks }\end{array}$ & & \\
\hline $\begin{array}{l}\text { Idling and } \\
\text { minor } \\
\text { stoppages }\end{array}$ & \multirow{2}{*}{$\begin{array}{l}\text { Performances } \\
\text { Losses }\end{array}$} & \multirow{2}{*}{$\begin{array}{l}\text { Performance efficiency }=(\mathrm{Net} \\
\text { Operating time/ Operating } \\
\text { Time }) \text { x } 100\end{array}$} \\
\hline $\begin{array}{l}\text { Reduced } \\
\text { Speed }\end{array}$ & & \\
\hline $\begin{array}{l}\text { Defects in } \\
\text { process }\end{array}$ & $\begin{array}{l}\text { Quality } \\
\text { Losses }\end{array}$ & $\begin{array}{l}\text { Rate of Quality = (Actual } \\
\text { work done/ Schedule work) x } \\
100\end{array}$ \\
\hline
\end{tabular}

\section{CONCLUSION}

1. By using Activity based costing method we have reduced cost due to downtime of equipment by about $35 \%$. This method is useful for all the construction projects those whose overhead cost is getting more in account of company.

2. Before using $\mathrm{ABC}$ method we were using Traditional method in which we used to cost $1,51,300$ as downtime cost whereas after using $\mathrm{ABC}$ method the downtime cost were reduced to 98,050 . This help us in reducing the total amount up to 53,250 .

3. As the downtime is decreased the overall delay in work due to downtime is decreased which results in the Timely completion of the project.

4. Delay reduced due to downtime also helped us in fulfilling the RERA norms, budgetary completion of project.

5. Categorized different losses separately so that calculation of effective operating time of the machine can be calculated.

6. The same has been proposed to different builders to minimize the losses and increase the quality and efficiency of the project work.

7. Due to this systematic approach, the downtime that usually cost upto $30-35 \%$ of the construction cost can be easily reduced to $10 \%$ or less.

\section{REFERENCES}

[1] Mali Pritam A., (2015) "Effect of Construction Equipment On Production In Building Construction Project" International Journal Of Engineering Sciences \& Research
Technology ISSN:::2277-9655 (I2or), Publication Impact Factor: 3.785

[2] Prasannasangeetha.A, (2015) "Equipment Management In Construction Sector" International Journal Of Science And Engineering Research (Ij0ser), Vol 3 Issue

[3] Amir H. B., (2013) "Simulation-Based Evaluation Of Fuel Consumption In Heavy Construction Projects By Monitoring Equipment Idle Times" Proceedings Of The 2013 Winter Simulation Conference R. Pasupathy, S.-H. Kim, A. Tolk, R. Hill, And M. E. Kuhl, Eds

[4] Rickey A. Cook, (1999) "A Crane And Heavy Equipment Maintenance Plan For Improving Safety And Efficiency" The Graduate College University Of WisconsinStout

[5] Ilias Naskoudakis, (2016) "A Thematic Review Of The Main Research On Construction Equipment Over Recent Years" 47(2), Pp. 110-118, 2016 Doi: 10.3311/Ppar.10384 Creative Commons Attribution

[6] D.G. Proverbs, G. D. Holt And H. Y. Cheok "Construction Industry Problems: The Views Of Uk Construction Directors" Built Environment Research Unit, School Of Engineering And The Built Environment, University Of Wolverhampton, West Midlands, Uk, Wv1 $1 \mathrm{sb}$, Uk.

[7] Urmila A Mahadik, (2015) "Cost Reduction In Construction Projects" Inte Rnational Journal Of Engineering Technology, Management And Applied Sciences Www.Ijetmas.Com Volume 3, Special Issue, ISSN:: 23494476

[8] Tsado, Theophilus Yisa, (2014) "Equipment Maintenance: An Effective Aspect Of Enhancing Construction Project Profitability" International Journal Of Engineering Science Invention ISSN:: (Online): 2319 - 6734, ISSN:: (Print): 2319- 6726 Www.Ijesi.Org Volume 3issue 4 \| Pp.34-41

[9] D. B. Phadatare, (2016) "Impact Of Construction Equipmentes On Building Site Productivity" International Journal Of Civil Engineering And Technology (Ijciet) Volume 7, Issue 4,

[10] Mr. Nilesh Ayane, (2015) "Review Study On Improvement Of Overall Equipment Effectiveness In Construction Equipments" Ijedr | Volume 3, Issue 2 | ISSN:::2321-9939

[11] Prajeesh. V. P, (2016) "Management Of Equipment \& Machinery In Construction" Ijiset - International Journal Of Innovative Science, Engineering \& Technology, Vol. 3 Issue [12] Mr. Pratik Desai, (2017) "Overall Equipment Effectiveness In Construction Equipments"International Research Journal Of Engineering And Technology (Irjet) EISSN:::2395 -0056 Volume: 04 Issue: 01 | Www.Irjet.Net PISSN:::2395-0072"

[13] Jariwala Siddharth, (2015) "A Critical Literature Review On Comparitive Analysis Of Construction Equipments -Rent And Buy" Journal Of International 
Academic Research For Multidisciplinary Impact Factor 1.625, ISSN:::2320-5083, Volume 2, Issue 12

[14] Marie-Claude Nadeau “A Dynamic Process-Based Cost Modeling Approach To Understand Learning Effects In Manufacturing" Engineering Systems Division, Massachusetts Institute Of Technology, 77 Massachusetts Avenue, Cambridge, Ma 02139, Usa

[15] Kunal R Ghadge,(2013)“'Construction Equipment Management For Construction Of Dam Site" International

Journal Of Science And Research (Ijsr) ISSN:: (Online): 2319-7064 Index Copernicus Value (2013): 6.14 |Impact Factor (2013): 4.438 